\title{
An experimental study using SXES: Evaluation and applications for a new analysis method to study the self-absorption effects of Fe L-emission
}

Takaomi D. Yokoyama ${ }^{1}$, Hideyuki Takahashi ${ }^{1}$, Ichiro Ohnishi ${ }^{1}$, Vernon E. Robertson ${ }^{2}$ and Peter McSwiggen $^{2}$

${ }^{1}$ JEOL Ltd., United States, ${ }^{2}$ JEOL USA Inc., United States

A Soft X-ray emission spectrometer (SXES) for electron probe micro analyzers (EPMA) and scanning electron microscopes (SEM) is a recently developed wavelength dispersive spectrometer for measuring electron beam induced soft X-rays ${ }^{1}$ and separating them based on wavelength using static, varied-linespacing diffraction gratings. The SXES spectrometer enables us to obtain partial density of states (DOS) of valence bands from areas of interest identified by electron beam imaging. SXES analyses can be used to probe solid state effects and the energy state of bonding electrons ${ }^{1,2}$.

Determination of Fe oxidation states in oxides and silicate minerals using soft X-ray measurements in an EPMA has been investigated since the 1970's. The technique is based either on a change of the intensity or the wavelength (peak position) of soft X-ray emission lines. Albee \& Chodos $(1970)^{3}$ reported that the relative intensity of $\mathrm{Fe} L \alpha$ and $L \beta$ X-ray emission peaks measured with an EPMA differ based on valence states and bond association. This method has been qualitatively useful to analyze $\mathrm{Fe}$ oxides and some silicates $^{3,4,5}$. Höfer et al., (1994, 2000) established the method that exploits a concomitant change of both the intensity and wavelength of the Fe $L$-emission" 6,7 Currently, this "flank method" is available for determining the Fe oxidation states of Fe oxides, in pyroxenes and garnets ${ }^{8,9}$.

Peak shape changes of soft X-ray emission bands of first transition elements (including Fe) with the matrix composition and the excitation conditions are related to the self-absorption phenomena ${ }^{8,10}$. The effect of self-absorption on the emission spectrum can be evaluated by calculating the difference between the two spectra obtained by changing the electron beam accelerating voltage $\mathrm{e}^{5,8,10,11}$. By using this evaluation method, it is known that the $L 2$ and $L 3$ absorption edges of Fe create a change in the emission spectrum. We studied the line shapes of Fe soft X-ray emission bands of metals, oxides, sulfides and some silicates using SXES spectroscopy.

Iron oxide samples $\left(\mathrm{FeO}, \mathrm{Fe}_{3} \mathrm{O}_{4}\right.$ and $\left.\mathrm{Fe}_{2} \mathrm{O}_{3}\right)$ were measured to follow up on previous studies. The silicate samples are fayalite $\left(\mathrm{Fe}_{2} \mathrm{SiO}_{4}\right)$, almandine $\left(\mathrm{Fe}_{3} \mathrm{Al}_{2}\left(\mathrm{SiO}_{4}\right)_{3}\right)$, hedenbergite $\left(\mathrm{CaFeSi}_{2} \mathrm{O}_{6}\right)$, andradite $\left(\mathrm{Ca}_{3} \mathrm{Fe}_{2}\left(\mathrm{SiO}_{4}\right)_{3}\right)$. Fe $L$-emission spectra were measured using the extended range Soft X-ray Emission Spectrometer (JEOL SS-94040SXSER) paired with a new field emission electron probe microanalyzer (JEOL JXA-iHP200F). The diffraction grating used was the JS2000 with an energy dispersive range of $350-2300 \mathrm{eV}$ and an energy resolution of $5.0 \mathrm{eV}$ at FWHM of Fe $L \alpha$. The other diffraction grating in this spectrometer, the JS300N, (not used for these analyses) has an energy dispersive range of 100-400 eV and an energy resolution of $1.2 \mathrm{eV} \mathrm{FWHM} \mathrm{at} \mathrm{Zr-Mz.} \mathrm{The} \mathrm{calibration} \mathrm{energy} \mathrm{was} \mathrm{set} \mathrm{to} 705.0 \mathrm{eV}$ on the Fe $L \alpha$ peak position of a metallic iron standard at $1 \mathrm{kV}$ accelerating voltage (to minimize the absorption effect). The measured peaks of Fe $L$-emission spectra are fitted with a least-square method using a pseudo-Voigt function. Background intensities are approximated with a linear function. 
The self-absorption effect was visualized by calculating the differences between the normalized emission spectra obtained at different accelerating voltages. We employed normalization to have the same peak height of the Fe $L \alpha$ peaks allowing comparison of the self-absorption effect with peak shape changed at different accelerating voltages. The calculated absorption spectra showed different peak energies for each mineral species (Fig. 1). The absorption peak position shifts with the SXES tends to be consistent with the Fe L2,3 edge obtained by transmission electron microscope-electron (TEM) energy loss near edge structure (TEM-ELNES) method ${ }^{12}$. Moreover, calculated SXES absorption spectra have different fine structures. (Fig. 2). This suggests that SXES absorption spectra can be applied to the new X-ray absorption spectroscopy like ELNES and/or X-ray absorption near edge structure (XANES).
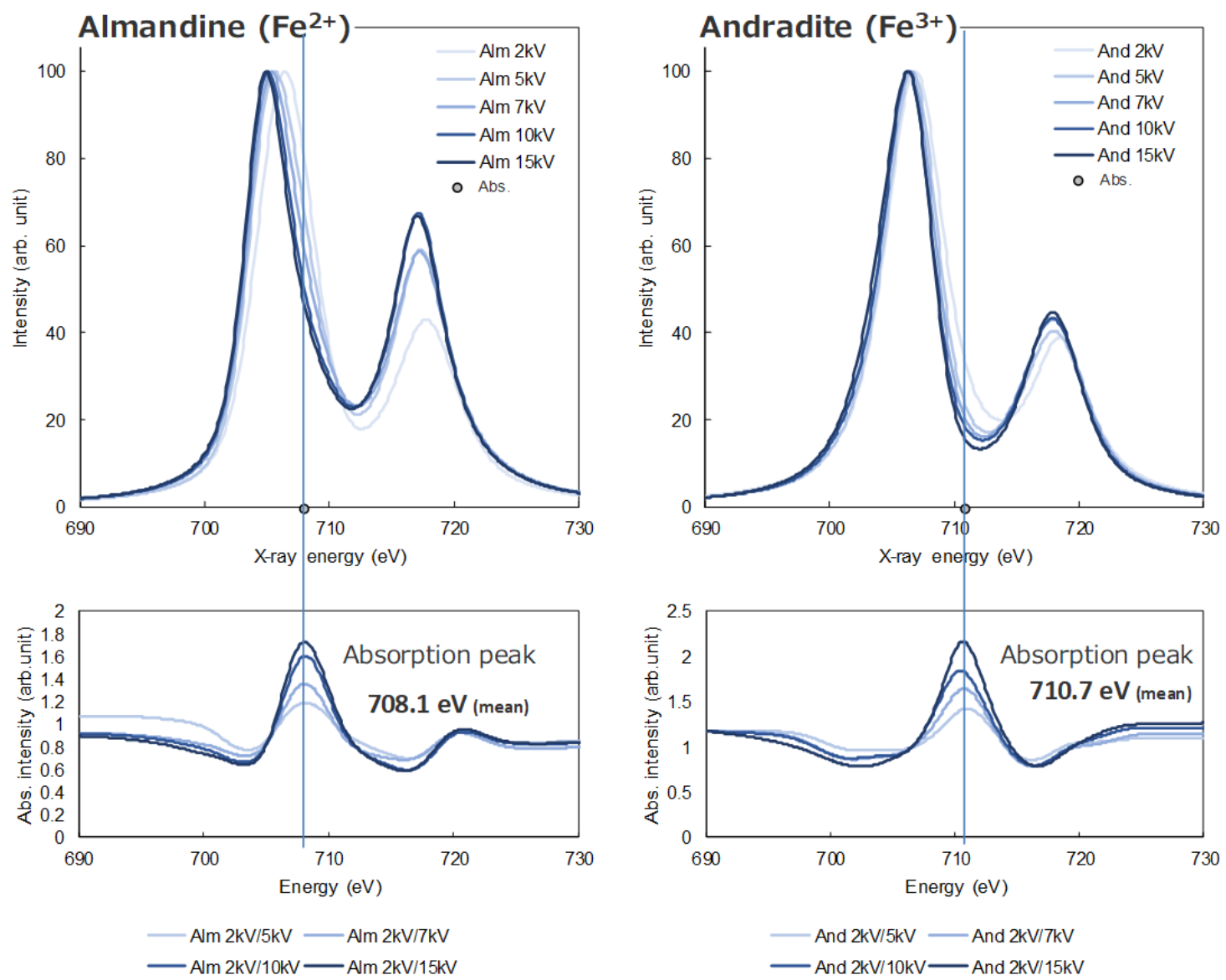

Figure 1. Measured Fe L-emission and calculated absorption spectra of two garnet type minerals (almandine and andradite). 


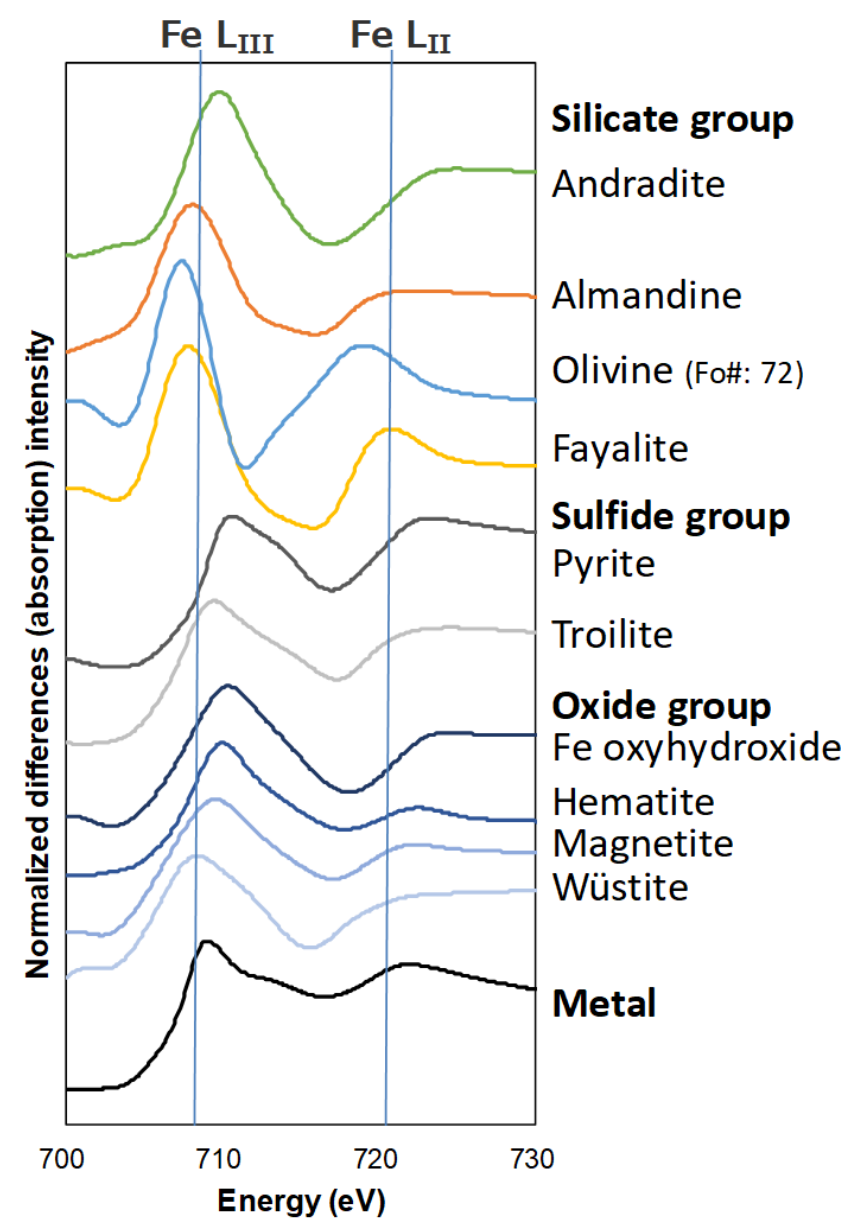

Figure 2. Calculated Fe absorption spectra of measured iron minerals $(5 \mathrm{kV} / 15 \mathrm{kV})$.

\section{References}

1. Takahashi, H. et al. IOC Conf. Ser. Mater. Sci. Eng. 109, 012017 (11 pages) (2016)

2. Takahashi, H. et al. EMAS 2017 Proceedings. 458-459 (2017)

3. Albee, A. L. \& Chodos, A. Mineral. J. Earth Planet. Mater. 55, 491-501 (1970)

4. Lamb, M. W. et al. Min. 97, 951-961 (2012)

5. T. et al. J. Mineral. Petrol. Sci. 108, 25-36 (2013)

6. Höfer, H. E. et al. J. Mineral. 6, 407-418 (1994)

7. Höfer, H. E. et al. J. Mineral. 12, 63-71 (2000)

8. Höfer, H. E. \& Brey, G. P. Mineral. 92, 873-885 (2007)

9. Borfecchia, E. et al. Anal. At. Spectrom. 27, 1725-1733 (2012)

10. Remond, G. et al. Microbeam and Nanobeam analysis. 13, 61-86 (1996)

11. Remond, G. et al. Res. Natl. Inst. Stand. Technol. 107(6), 509-529 (2002)

12. Van Aken, P. et al. Chem. Minerals. 25, 323-327 (1998) 